\title{
A educação ambiental nas Escolas Municipais de Manaus (AM): um estudo de caso a partir da percepção dos discentes
}

Environmental education in Municipal Schools of Manaus: a case study from the perception of students

\author{
Patrícia Auxiliadora Ribeiro de França', Maria da Glória Vitório Guimarães²
}

\author{
'Mestranda em Engenharia de Produção na Universidade Federal do Amazonas - UFAM. Grupo de Estudo de Resíduos - GERES/ Cnpq, \\ Universidade Federal do Amazonas - AM - Brasil \\ ${ }^{2}$ Doutora,Professora Adjunta do Departamento de Administração da Universidade Federal do Amazonas - AM -Brasil
}

\begin{abstract}
Resumo
Este trabalho teve como ponto de partida encontrar resposta à seguinte problematização: até que ponto as escolas municipais têm contribuído para promover a educação ambiental? Em decorrência de tal pergunta, o trabalho teve como objetivo geral verificar se os projetos e ações em educação ambiental nas escolas municipais trazem resultados significativos que se traduzam em práticas pessoais no dia a dia dos seus discentes. Para tanto, foi realizado um estudo de caso, com pesquisa empírica do tipo descritiva, sobretudo na forma de trabalho de campo. Os principais resultados se mostraram concernentes com as abordagens de importantes autores da literatura sobre o assunto. Pode-se concluir que as ações de educação ambiental promovem mudanças de comportamento e despertam nos estudantes certo interesse para encontrar soluções para as problemáticas ambientais, todavia, para além do reconhecimento de valor e do interesse que os participantes têm sobre as questões ambientais, é necessário que as escolas avancem e busquem desenvolver novas ações.
\end{abstract}

Palavras-chave: Educação Ambiental Escolar; Percepção dos discentes; Escolas Municipais de Manaus.

\begin{abstract}
This work was the starting point to find answers to the following problematic: the extent to which public schools have contributed to promote environmental education? Due to such a question, the work aimed to verify if the actions and projects in environmental education in schools municipal bring significant results that translate into personal practices in day to day life of its students. Therefore, we conducted a case study with a descriptive empirical research, especially in the form of field work. The main results were concerned with the approaches of major authors of the literature on the subject. It can be concluded that the environmental education and promote behavioral changes in students arouse some interest to find solutions to environmental problems, however, beyond the recognition of value and interest of the participants have on environmental issues, it is necessary that schools seek to advance and develop new actions.
\end{abstract}

Keywords:Environmental Education School; Perception of students; Municipal Schools of Manaus. 


\section{INTRODUCCÃO}

Nas últimas décadas vêm se intensificando as preocupações relacionadas às questões ambientais e, juntamente com isso, as iniciativas de variados setores da sociedade, entre eles as escolas, para o desenvolvimento de atividades e projetos no intuito de educar as comunidades, procurando sensibilizá-las para a modificação de atitudes e posturas que sejam benéficas ao equilíbrio ambiental.

De acordo com Dias (1992), as escolas constituem espaços privilegiados na implementação de atividades que propiciem essa reflexão. Além disso, os estudantes necessitam de atividades de sala de aula e atividades de campo com projetos e ações orientados para uma maior participação que levem à autoconfiança, a atitudes positivas e ao comprometimento pessoal com a proteção ambiental implementados de modo interdisciplinar.

Visando abordar especificamente a ideia que formam os estudantes das Escolas Municipais de Manaus acerca da educação ambiental tem-se como problema de pesquisa o seguinte: até que ponto as escolas municipais têm contribuído para promover a Educação Ambiental (EA)?

Acredita-se que a educação ambiental quando praticada no ambiente educacional abre espaço para os estudantes conhecerem a problemática ambiental, incentivando-os a desenvolver uma nova maneira de pensar para agir de forma integrada e polivalente frente aos complexos problemas globais.

Isto posto, este trabalho tem como objetivo geral verificar, a partir da percepção dos discentes, se os projetos e ações de educação ambiental nas Escolas Municipais de Manaus trazem resultados significativos que se traduzam em práticas pessoais no dia a dia dos estudantes. Especificamente pretende-se identificar: se ocorrem reflexões e mudanças de atitudes referentes as questões ambientais no cotidiano dos discentes; o grau de interesse dos estudantes em relação às questões ambientais; como os estudantes percebem os problemas ambientais e o que fazem para solucioná-los; além de verificar quais são as ações ambientais praticadas pelas escolas.

Pelos argumentos anteriores é possível expor que a justificativa pela escolha do tema dá-se por ser de suma importância conhecer a percepção dos discentes sobre os efeitos positivos gerados aos mesmos e advindos da implementação de projetos e ações voltados para a preservação do meio ambiente pelas escolas estudadas.

\section{EDUCAÇ̃̃O AMBIENTAL NO BRASIL, EDUCAÇÃ O AMBIENTAL ESCOLAR E A PERCEPÇÃO AMBIENTAL}

A abordagem da temática ambiental vinculada ao modo como os discentes percebem-na, exige tratar da mesma no contexto das escolas, pondo em evidência ações de educação ambiental que promovem o exercício da cidadania, fortalecendo o processo de ensino e aprendizagem para a melhoria da qualidade de vida, conservação e preservação do meio ambiente. Tais aspectos são abordados a seguir:

\section{I. A institucionalização da educação ambiental no Brasil}

A oficialização da EA no Brasil aconteceu por meio da lei federal de $\mathrm{n}^{\circ} 6.938$ de 1981 , que criou a Política Nacional do Meio Ambiente (PNMA), onde foi estabelecida a necessidade de inclusão da educação ambiental em todos os níveis de ensino. Reforçando essa tendência, a Constituição Federal, em 1988, estabeleceu, no artigo 225, inciso VI:

Art. 225 - Todos têm direito ao meio ambiente ecologicamente equilibrado, bem de uso comum do povo e essencial à sadia qualidade de vida, impondo-se ao poder público e à coletividade o dever de defendê-lo e preservá-lo para as presentes e futuras gerações. (BRASIL, Constituição Federal, 2008).

Em 1994, foi criado o Programa Nacional de Educação Ambiental (PRONEA), cujas ações destinam-se a assegurar, no âmbito educativo, a integração equilibrada das múltiplas dimensões da sustentabilidade - ambiental, social, ética, cultural, econômica, espacial e política - ao desenvolvimento do País.

Em 1997 foram aprovados pelo Conselho Nacional de Educação os Parâmetros Curriculares Nacionais (PCN) que se constituem em um subsídio para apoiar a escola na elaboração do seu projeto educativo, inserindo procedimentos, atitudes e valores no convívio escolar, bem como a necessidade de tratar de alguns temas sociais urgentes, de abrangência nacional, denominados como temas transversais. (HENRIQUES et al, 2007).

Em 1999, foi aprovada a Lei ${ }^{\circ} 9.795$, que instituiu a Política Nacional de Educação Ambiental (PNEA). Esta lei estabelece políticas, 
ações estratégicas oficiais da educação ambiental e definições, conforme previsto na Lei, cap. I, art. $1^{\circ}$ :

Entende-se por educação ambiental os processos por meio dos quais o indivíduo e a coletividade constroem valores sociais, conhecimentos, habilidades, atitudes e competências voltadas para a conservação do meio ambiente, bem de uso comum do povo essencial a sadia qualidade de vida e sua sustentabilidade (BRASIL, Lei ${ }^{\circ}$ 9.795/99, cap. I, art. $1^{\circ}$ ).

Em virtude disto, a educação ambiental deverá estar presente em todos os níveis e modalidades do processo educativo, seja ele de caráter formal (educação básica, educação superior, educação especial, educação profissional, e educação de jovens e adultos) e não formal (ações e práticas educativas voltadas à sensibilização da coletividade sobre as questões ambientais).

Vale ressaltar que a dimensão ambiental deve constar dos currículos de formação de professores, em todos os níveis e em todas as disciplinas, sendo que "os professores em atividade devem receber formação complementar em suas áreas de atuação, com o propósito de atender adequadamente ao cumprimento dos princípios e objetivos da Política Nacional de Educação Ambiental" (BRASIL, Lei nº 9.795/99, art. 11).

\subsection{A educação ambiental escolar}

Para Giesta (2009) a educação ambiental é um conjunto de atividades que busca informar e sensibilizar as pessoas sobre a complexa temática ambiental, estimulando o envolvimento em ações que promovam hábitos sustentáveis de uso dos recursos naturais, além de propiciar reflexões sobre as relações do ser humano com o meio ambiente.

Neste contexto, a escola, conforme Effting (2007), deve sensibilizar o aluno a buscar valores que conduzam a uma convivência harmoniosa com o ambiente e as demais espécies que habitam o planeta, auxiliando-o a analisar criticamente os princípios que tem levado à destruição inconsequente dos recursos naturais e de várias espécies.

Dentro da escola, devem-se encontrar meios efetivos para que cada aluno compreenda os fenômenos naturais, as ações humanas e sua consequência para consigo, para sua própria espécie, para os outros seres vivos e o ambiente. É fundamental que cada aluno desenvolva as suas potencialidades e adote posturas pessoais e comportamentos sociais construtivos, colaborando para a construção de uma sociedade justa, em um ambiente saudável
(EFFING, 2007).

Segundo Penatti e Silva (2008), a educação ambiental conduz os estudantes a uma mudança de comportamento e atitudes em relação ao meio ambiente interno e externo das suas escolas, despertando o interesse em cada discente na ação e busca de soluções concretas para os problemas ambientais que ocorrem principalmente no seu dia a dia.

De acordo com Reigota (2009), a educação ambiental conta com vários recursos didáticos a serem empregados no ambiente escolar. Entre eles considera a própria aula dada desprovida de grandes apetrechos, mas repleta de possibilidades de diálogos e debates de posições diferentes e aprofundados. Contudo esta não deve ser esporádica, mas estar incluída nas práticas pedagógicas cotidianas das mais diversas disciplinas, ou seja, as questões ambientais não devem surgir apenas em algumas datas comemorativas ou disciplinas específicas, mas estar presente durante a vida escolar do discente.

Por outro lado, Barros et al. (2009) sugerem, para além das aulas ministradas, outras formas de trabalhar a educação ambiental na escola como: caminhadas no entorno da escola objetivando mostrar a realidade na qual os estudantes estão inseridos, a promoção de palestras e grupos de debate (escola/comunidade) afim de aproximar a comunidade da vida escolar dos estudantes, além de músicas, horta escolar, desfile cívico, dança, produção de mudas, gincana cultural, teatro, confecção de cartazes, murais e realização de campanhas.

De acordo com Zuben (1998), projetos de coleta seletiva nas escolas são muito importantes, pois incentivam os estudantes desde já a separarem o lixo, levando esse hábito para suas casas. É neste sentido que a prática da coleta seletiva de materiais, e posteriormente sua reciclagem, também funciona como um processo de educação ambiental na medida em que sensibiliza os estudantes sobre os problemas do desperdício de recursos naturais e da poluição causada pelos resíduos, fortalecendo, desta forma, comunidades locais e habilitando-as a cuidar dos seus próprios ambientes.

Assim sendo a escola, de acordo com Silva et al. (2010), é o espaço social e o local onde o aluno será sensibilizado para as ações ambientais e fora do âmbito escolar ele será capaz de dar sequência ao seu processo de socialização. Comportamentos ambientalmente corretos devem ser aprendidos na prática, no cotidiano da vida escolar, contribuindo para a formação de 
cidadãos responsáveis.

\subsection{Percepção ambiental}

Para quantificar um fenômeno ambiental é necessário percebê-lo. A palavra percepção é derivada do latim perceptione e que de acordo com Ferreira (1999) é ato, efeito ou faculdade de perceber. Já para Bock et al. (2002) a percepção nada mais é senão um processo que vai desde a recepção do estímulo pelos órgãos dos sentidos até a atribuição de significados a esse mesmo estímulo.

Desse modo, a percepção ambiental, de acordo com Fernandes et al. (2010), pode ser definida como sendo uma tomada de consciência do ambiente pelo homem, ou seja, o ato de perceber o ambiente que se está inserido, aprendendo a proteger e a cuidar do mesmo. Cada indivíduo percebe, reage e responde diferentemente às ações sobre o ambiente em que vive. As respostas ou manifestações daí decorrentes são resultado das percepções (individuais e coletivas), dos processos cognitivos, julgamentos e expectativas de cada pessoa.

Diante deste contexto, o estudo da percepção ambiental, principalmente no ambiente escolar, é de fundamental importância para que possamos compreender melhor as inter-relações entre o homem e o ambiente, suas expectativas, anseios, satisfações e insatisfações, julgamentos e condutas.

A educação e percepção ambiental despontam como armas na defesa do meio natural, e ajuda a reaproximar o homem da natureza, garantindo um futuro com mais qualidade de vida para todos, já que desperta uma maior responsabilidade e respeito dos indivíduos em relação ao ambiente em que vivem.

\section{TRAJETÓRIA METODOLÓGICA}

A pesquisa, enfatiza Prestes (2007), designa um conjunto de atividades que têm como finalidade descobrir novos conhecimentos. Daí a necessidade de assegurar sua dimensão de cientificidade, descrever, de modo o mais preciso possível, o que ela é e como se deu sua realização. Neste sentido, ainda com base em Prestes (2007), considerando o objetivo deste trabalho, define-se como pesquisa empírica, posto que se volta para esclarecer a problemática observada, objetivando codificar o lado mensurável da realidade.

No que se refere à forma de estudo do objeto da pesquisa, ela é do tipo descritiva. Isto porque o fenômeno sob estudo foi observado, registrado, analisado e interpretado sem qualquer interferência das pesquisadoras. Quanto ao objeto de estudo a pesquisa revela-se, sobretudo, de campo, haja vista o uso que se faz de questionários autoadministrados, por meio dos quais ocorreu a coleta dos dados, investigando os participantes em seus próprios meios. Estas duas últimas classificações, vale dizer, também tendo como referência o que esclarece Prestes (2007).

Tendo como locus a cidade de Manaus, a pesquisadora desenvolveu a coleta de dados, no mês de agosto de 2013, junto aos discentes do $7^{\circ}$ ano do ensino fundamental de seis Escolas Municipais, que correspondem as Zonas: Norte (26), Sul (28), Leste (31), Oeste (38), Centro-oeste (21) e Centro-sul (27). O instrumento adotado foi um questionário, contendo questões de múltipla escolha que são perguntas fechadas, mas que apresentam uma série de possíveis respostas, abrangendo várias facetas a respeito do assunto.

Os questionários foram aplicados nas referidas Escolas, perfazendo um total de cento e setenta e um (171) estudantes que responderam o instrumento. Os dados obtidos foram analisados a partir da estatística descritiva, foram interpretados ou representados a fim de se obter uma análise de todas as áreas da cidade, como se apresenta e se discute a seguir.

\section{RESULTADOS E DISCUSSÕES}

A compreensão e a percepção dos estudantes para lidar com as questões ambientais foram abordadas de várias maneiras. Os discentes, primeiramente, foram perguntados em relação ao que eles consideravam problemas ambientais, dando-lhes as opções de escolher até três respostas. A Figura 1 mostra que dos 171 participantes, a grande maioria considerou como problemas ambientais a poluição das águas (90\%), lixo (49\%), fumaça de carro (46\%) e esgoto a céu aberto (42\%). Já contaminação do solo (31\%), falta de água (16\%), enchentes $(16 \%)$, poeira $(5 \%)$ e buzina $(3 \%)$ foram os menos indicados. Estes resultados mostram as diferentes formas de perceber às ações sobre o ambiente em que cada indivíduo vive, como já apontavam Fernandes et al. (2010).

Para avaliar de quem era a responsabilidade em resolver os problemas ambientais, os dados, como se vê na Figura 2, mostram, em grande maioria, que os participantes apontaram o povo $(72 \%)$ como um dos principais responsáveis, seguido de 


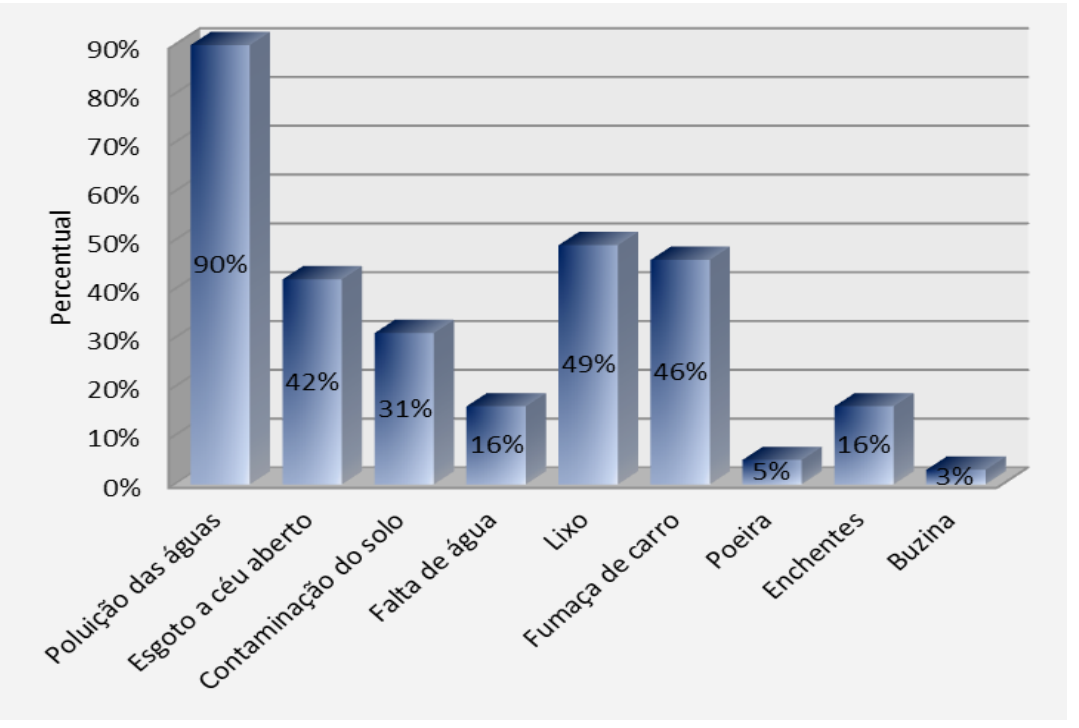

Figura 2 - Resolver os problemas ambientais

associação de moradores (38\%), políticos (35\%) e eles mesmos (32\%). Já a responsabilidade aferida as organizações ecológicas (23\%), as escolas $(16 \%)$, os cientistas $(7 \%)$ e a igreja ( $2 \%)$ foram os menos apontados. Nota-se com tais resultados que os estudantes confirmam que a responsabilidade em resolver os problemas ambientais é de todos, como preceitua a Constituição Federal de 1988, em seu artigo 225, inciso VI "Todos têm direito ao meio ambiente ecologicamente equilibrado, bem de uso comum do povo e essencial à sadia qualidade de vida, impondo-se ao poder público e à coletividade o dever de defendê-lo e preservá-lo para as presentes e futuras gerações".
Ao serem questionados sobre as atitudes negativas em relação ao meio ambiente que já foram abandonadas pelos participantes, observa-se, na Figura 3, que a grande maioria (61\%) afirma que deixou de desperdiçar água, 59\% dos respondentes deixou de jogar lixo no chão, $43 \%$ dos pesquisados não mais deixou as luzes ligadas e que $34 \%$ deixou de jogar lixo nos igarapés, rios ou lagos. Atitudes essas que, como bem destacou Giesta (2009), são advindas de processos de educação ambiental que buscam sensibilizar as pessoas sobre a complexa temática ambiental, estimulando-as para o envolvimento em ações que promovam hábitos sustentáveis de uso dos recursos naturais e

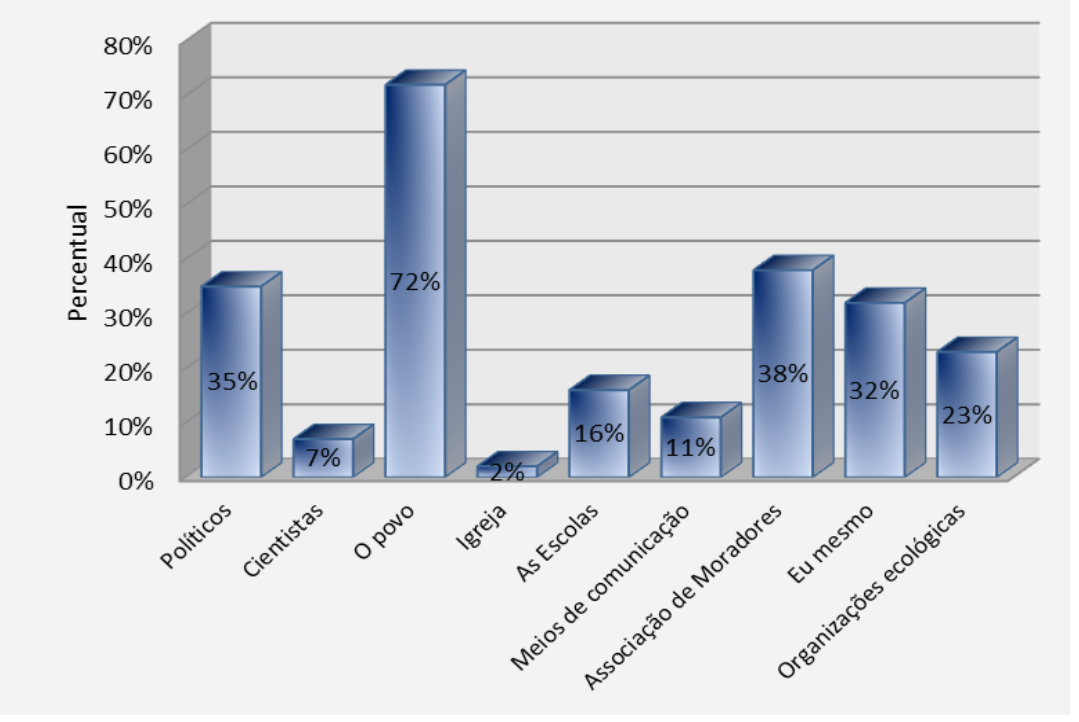

Figura 2 - Resolver os problemas ambientais 


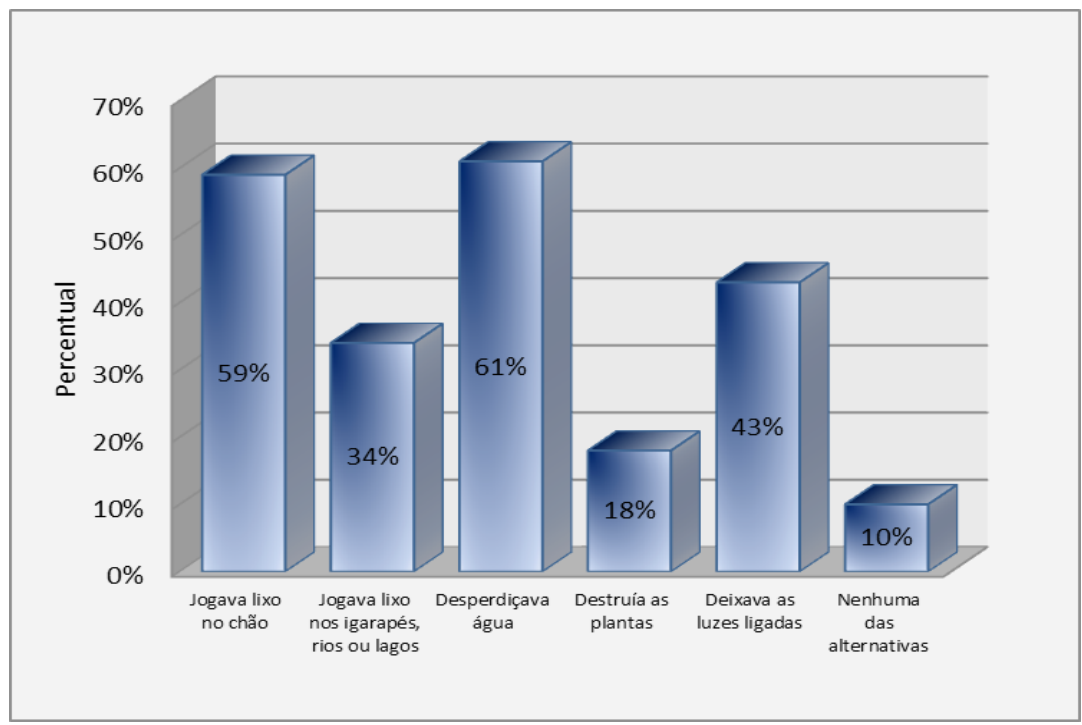

Figura 3 - Atitudes negativas abandonadas

o desenvolvimento de atividades de sensibilização e de mudanças de hábitos.

Objetivando ainda identificar as ações praticadas pelos estudantes para a proteção do meio ambiente, a Figura 4 mostra que $74 \%$ dos participantes dizem jogar o lixo em local adequado, $50 \%$ procuram não desperdiçar água e $34 \%$ dizem cuidar das plantas e árvores. Já respeitar os animais (29\%), desligar as luzes quando não está na sala (28\%), utilizar sua própria caneca na escola (22\%), evitar utilizar sacolas plásticas $(10 \%)$ e utilizar produtos sustentáveis (3\%) foram as ações menos apontadas. Nota-se que a grande maioria apontou como prática o descarte do lixo de forma correta, o que enfatiza as considerações de Zuben (1998) acerca de projetos de coleta seletiva nas escolas, pois incentivam os estudantes a separarem o lixo, levando esse hábito para suas casas.

Em seguida os discentes foram perguntados quais atividades são desenvolvidas por sua escola que visam à conscientização ambiental dos mesmos. Os dados da Figura 5 mostram que $53 \%$ dos respondentes dizem que sua escola realiza palestras, $40 \%$ dizem que realiza reciclagem e $30 \%$ dos respondentes dizem que realiza coleta seletiva. Todavia, nota-se também o desenvolvimento de outras atividades como apresentação

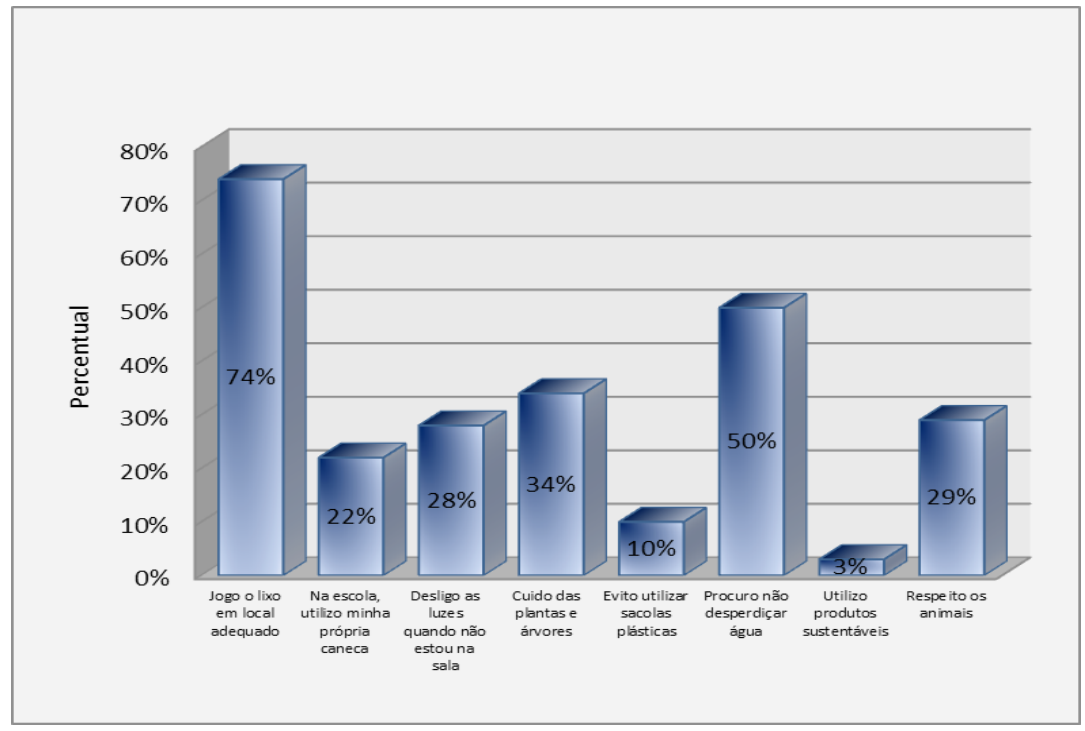

Figura 4 - Ações praticadas pelos discentes 


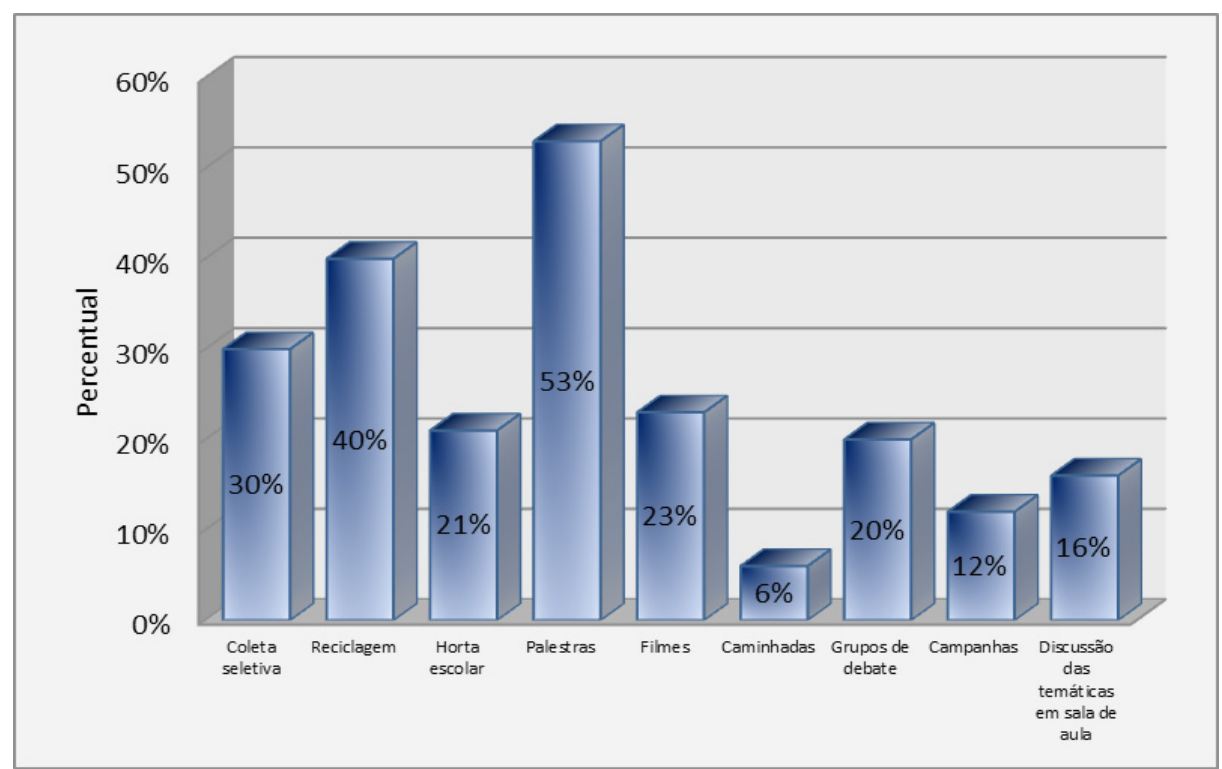

Figura 5 - Atividades desenvolvidas pela escola

de filmes (23\%), horta escolar (21\%), grupos de debate: escola e comunidade $(20 \%)$, discussão das temáticas ambientais em sala de aula (16\%), campanhas (12\%) e caminhadas (6\%). Ações estas que, como sugeriram Barros et al. (2009), são outras formas de trabalhar a educação ambiental na escola e como bem destacou Effing (2007), fazem com que os alunos desenvolvam as suas potencialidades e adotem posturas pessoais e comportamentos sociais construtivos, colaborando para a construção de uma sociedade mais justa, em um ambiente saudável.

Considerando a pergunta anterior os discentes foram indagados: "Com que frequência a sua escola promove ações que incentivam a conscientização ambiental?", 37\% dos respondentes apontaram que somente às vezes sua escola promove estas ações, $30 \%$ disseram que na maioria das vezes sua escola promove estas ações, seguido de 23\% que consideram que sua escola sempre promove atividades que são voltadas para a conscientização ambiental dos mesmos (Figura 6). Mas também houve respostas como raramente $(8 \%)$ e nunca (2\%). Enfatiza-se, que atualmente se faz necessário, como afirma Reigota (2009), que as práticas ambientais não devem ser esporádicas ou realizadas somente em datas específicas, mas

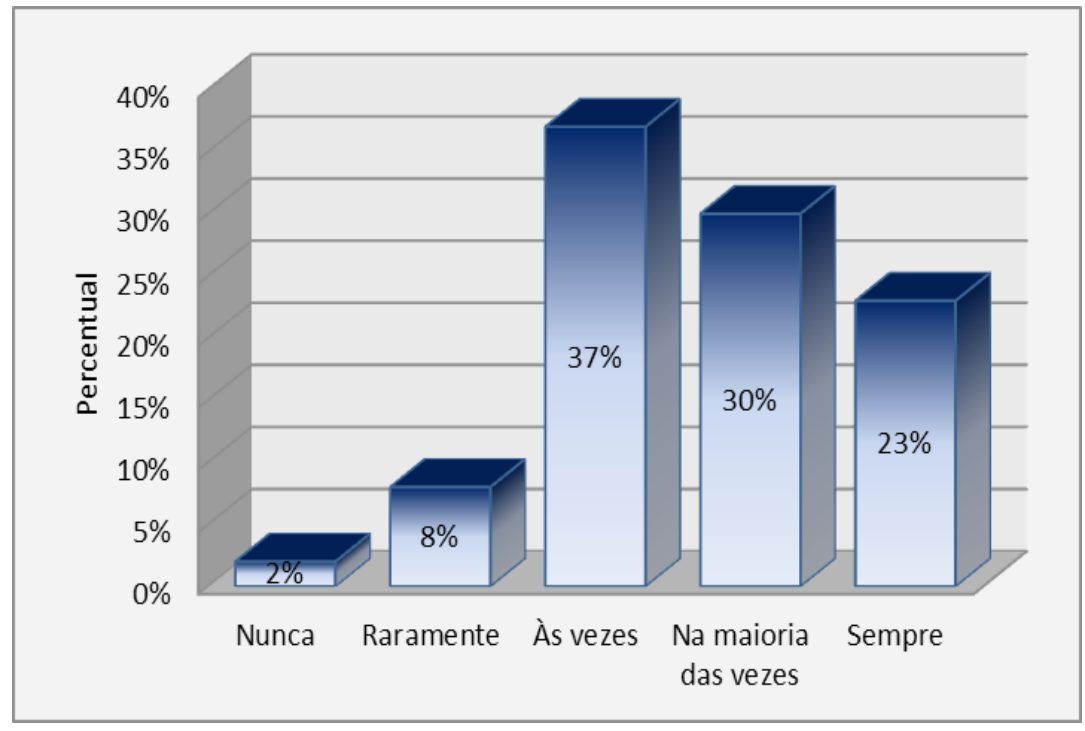

Figura 6 - Frequência das ações praticadas pela escola 


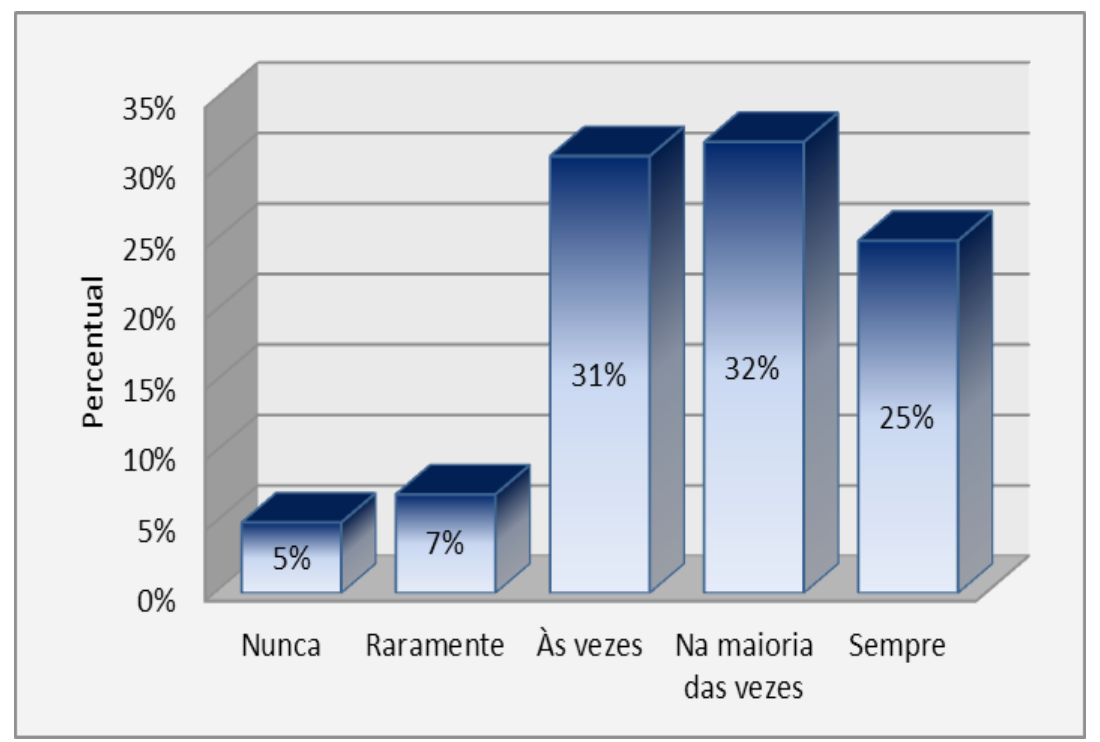

Figura 7 - Mudança de atitudes dentro da escola

devem estar incluídas no dia a dia dos discentes, e inseridas nas práticas pedagógicas cotidianas das mais diversas disciplinas.

$\mathrm{Na}$ Figura 7, observa-se que $88 \%$ dos participantes revelaram que as informações divulgadas sobre meio ambiente os motivam a mudar de atitude dentro da própria escola, onde $32 \%$ informaram na maioria das vezes, $31 \%$ às vezes e $25 \%$ sempre. Os percentuais obtidos na pergunta sobre mudança de atitude em casa (fora da escola), corroboram com os dados obtidos na Figura 8, cerca de $36 \%$ dos respondentes informaram que às vezes, as informações divulgadas sobre meio ambiente os motivam a mudar de atitude dentro de casa, $29 \%$ na maioria das vezes e $21 \%$ sempre percebem a mudança de atitude em casa devido informações recebidas pela escola. Tais dados confirmam que a educação ambiental conduz os estudantes a uma mudança de comportamento e atitudes em relação ao meio ambiente interno e externo das suas escolas, como já apontavam Penatti e Silva (2008).

A penúltima questão versa sobre a retransmissão das informações obtidas nos processos de educação ambiental na escola, para os amigos e para os familiares dos participantes. A Figura 9, como se vê, revela que $35 \%$ dos discentes dizem às vezes retransmitem informações recebidas na escola para seus amigos e familiares, $27 \%$ dizem que na maioria das vezes isto acontece e somente

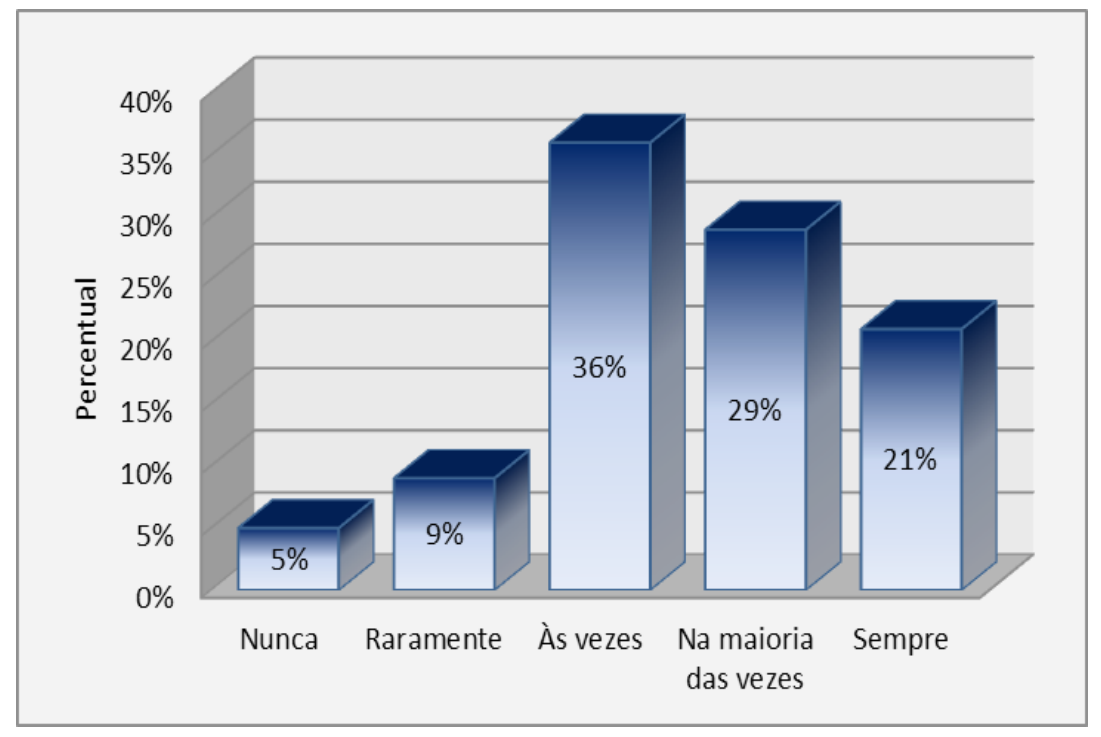

Figura 8 - Mudança de atitudes em casa 


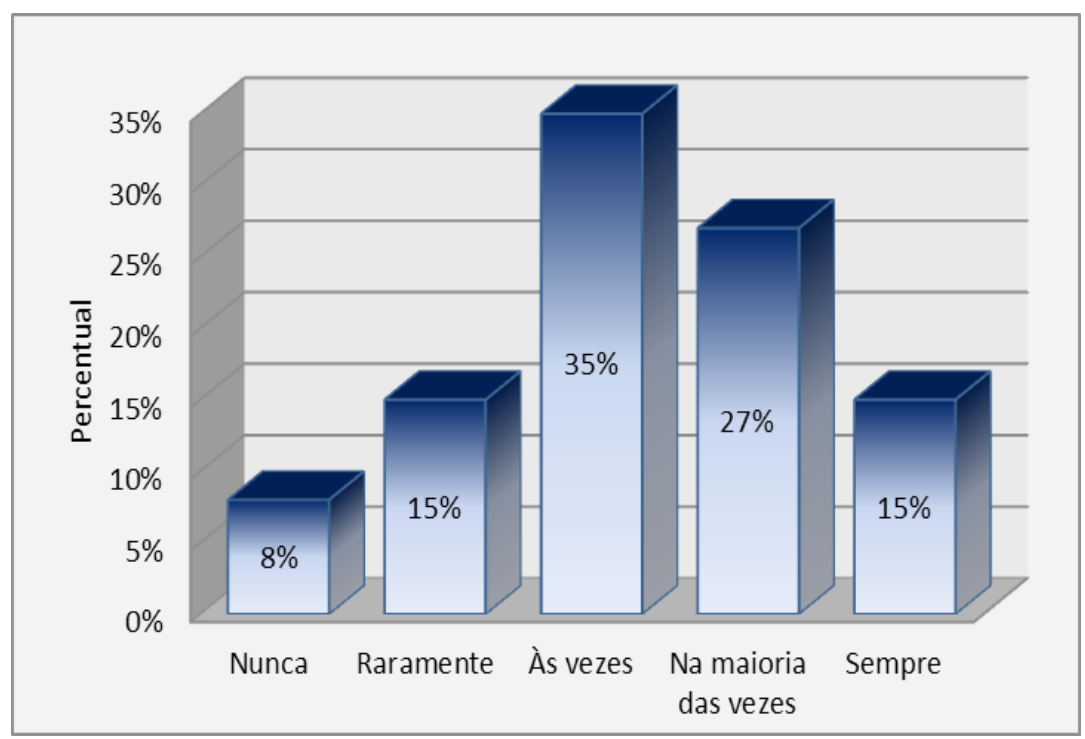

Figura 9 - Frequência das informações retransmitidas para amigos e familiares

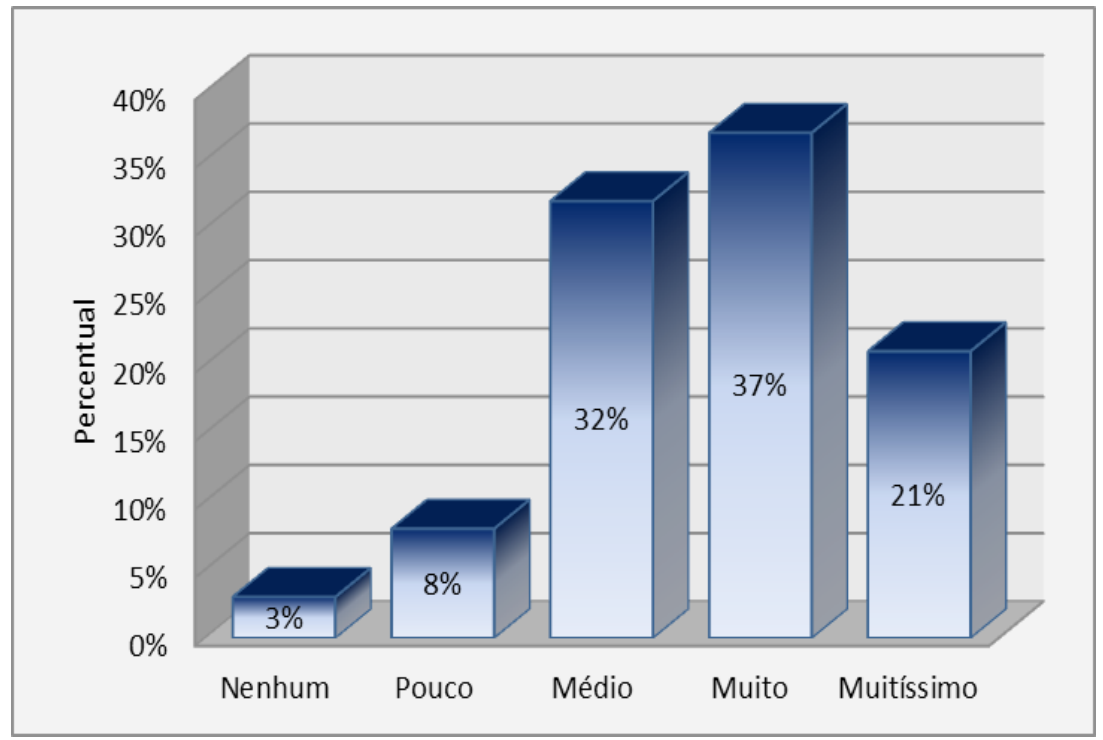

Figura 10- Grau de interesse em relação às questões ambientais

$15 \%$ revelam que sempre retransmitem informações das escolas para seus amigos ou familiares. Estes índices apontam um interesse de disseminar informações sobre a temática ambiental para aqueles que circundam os respondentes. Fato este que já havia sido destacado por Silva et al. (2010) e que, aqui, se confirma, pois, para estas autoras, a escola é o espaço social e o local onde o aluno será sensibilizado para as ações ambientais e fora do âmbito escolar ele será capaz de dar sequência ao seu processo de socialização.

A última questão buscou identificar qual o grau de interesse dos discentes em relação às questões ambientais. A distribuição percentual apre- sentada pelos respondentes, como se vê na Figura 10 , revela que $37 \%$ dos respondentes, seguido de $21 \%$, afirmam possuírem um elevado grau de interesse em relação às questões ambientais. Já $32 \%$ afirmam ter um interesse mediano e apenas $8 \%$ e $3 \%$ apontaram pouco ou nenhum interesse.

\section{CONCLUSÃO}

A escola é o ambiente ideal para se trabalhar conteúdos e metodologias adequadas para uma maior consciência ambiental, pois é o centro de formação educacional do cidadão, onde nasce 
à necessidade de ensinar e de tornar práticos os principais conceitos referentes ao meio ambiente, à cidadania e a conservação, na intenção de formar cidadãos sensibilizados com a causa ambiental.

Isto posto, considerando ter sido o objetivo geral deste trabalho o de verificar, a partir da percepção dos discentes, se os projetos e as ações de educação ambiental nas Escolas Municipais de Manaus trazem resultados significativos que se traduzam em práticas pessoais no dia a dia dos estudantes, bem como considerando os resultados aqui encontrados e discutidos, é possível concluir que os projetos e as ações de educação ambiental das escolas pesquisadas promovem mudanças de comportamento e despertam nos estudantes certo interesse para encontrar soluções para as problemáticas ambientais, onde adquirem condições de assumir o papel de agentes de mudança em qualquer contexto e situação, influenciando, inclusive, em suas práticas pessoais, bem como, adquirem a capacidade de disseminar informações sobre a temática ambiental para aqueles que os circundam, como seus amigos e familiares. Todavia estas ações não são apontadas pelos discentes como frequentes no seu cotidiano, sendo necessário que as escolas avancem mais ainda.

Tal avanço, aqui posto com o tom de recomendação, é aquele que coloca às escolas e aos que com ela estão envolvidos (pais, professores, diretores, pedagogos, poder público) para a necessidade de ações e planos voltados à preservação do meio ambiente inseridos no dia a dia dos estudantes, despertando, dessa forma, a conscientização para a ação e a busca de soluções concretas para os problemas ambientais.

Assim, considera-se que os objetivos deste trabalho foram alcançados, mas com expectativa de continuação da pesquisa, a fim de saber também a percepção de todos os atores envolvidos nesse processo (professores, diretores, pedagogos, pais, poder público). O trabalho desenvolvido até o presente momento serviu para tornar visíveis muitos aspectos que devem ser aprofundados.

\section{REFERÊNCIAS}

BARROS, Ana Lúcia; ARAÚJO, Charles Silva; SOUZA, Frida da Silva; POZZETTI, Gislaine Regina; SILVA, João Marcelo; SILVA, José Roselito Carmelo da; COSTA, Maria José Alencar; ROMÃO, Rosicleide; TORRES, Ranna; PRADO, Thelma; GUIDA, Vânia Marília Lima; BARRETO, Waldenice.
Agenda Ambiental Escolar. 2009. Disponível em: http://semed.manaus.am.gov.br/wp-content/uploads/2010/10/Revisada-18-de-maiode-2009.pdf. Acesso em: 7 de setembro de 2013.

BOCK, Ana Mercês Bahia; FURTADO, Odair; TEIXEIRA, Maria de Lourdes Trassi. Psicologias: uma introdução ao estudo de psicologia. $13^{a}$ ed. Reformada e ampliada - São Paulo:

Saraiva, 2002.

BRASIL. Constituição 1988. Constituição da República Federativa do Brasil. Brasília, DF: Senado. 1988.

BRASIL. Lei no 9.795, de 27 de Abril de 1999. Dispõe sobre a educação ambiental, institui a Política Nacional de Educação Ambiental e dá outras providências. Site da Presidência da República Federativa do Brasil. Disponível em: http://www.planalto.gov.br/ccivil_03/Leis/ L9795.htm. Acesso em: 27 de agosto de 2013.

DIAS, G. F. Educação Ambiental: princípios e práticas. São Paulo, Gaia, 1992.

EFFTING, Tânia Regina. Educação Ambiental nas Escolas Públicas: Realidade e Desafios. Marechal Cândido Rondon, 2007. Monografia (Pós Graduação em "Latu Sensu" Planejamento Para o Desenvolvimento Sustentável) - Centro de Ciências Agrárias, Universidade Estadual do Oeste do Paraná - Campus de Marechal Cândido Rondon, 2007.

FERREIRA, Aurélio Buarque de Holanda. Novo Aurélio século XXI: o dicionário da língua portuguesa. $3^{\mathrm{a}} \mathrm{ed}$. Totalmente revista e ampliada - Rio de Janeiro: Nova Fronteira, 1999.

FERNANDES, Roosevelt S.; SOUZA, Valdir José de; PELISSARI, Vinicius Braga; FERNANDES, Sabrina T. Uso da percepção ambiental como instrumento de gestão em aplicações ligadas às áreas educacional, social e ambiental. Disponível em: Acesso em: 3 de setembro de 2013.

GIESTA, Lílian Caporlíngua. Cartilha de Gestão Ambiental. 2009. Disponível em: http:// www2.ufersa.edu.br/portal/view/uploads/ setores $/ 241 /$ Cartilha $\% 20$ Gest $\%$ C3\%A3o\%20 
Ambiental.pdf. Acesso em: 6 de setembro de 2013.B

HENRIQUES, Ricardo; TRAJBER, Rachel; MELLO, Soraia; LIPAI, Eneida M.; CHAMUSCA, Adelaide. Educação Ambiental: aprendizes de sustentabilidade. Brasília, 2007.

KIST, Anna Christine Ferreira. Concepções e Práticas de Educação Ambiental: uma Análise a partir das Matrizes Teóricas e Epistemológicas Presentes em Escolas Estaduais de Ensino Fundamental de Santa Maria-RS. Santa Maria: UFSM, 2010. Dissertação (Mestrado) - Programa de Pós-Graduação em Geografia e Geociências, Universidade Federal de Santa Maria, Santa Maria, 2010. Disponível em: http:// w3.ufsm.br/ppggeo/files/dissertacoes_06-11/ Anna\%20Cristine.pdf. Acesso em: 24 de agosto de 2013.

PENATTI, Fabio Eduardo; SILVA, Paulo Marcos. Coleta Seletiva como Processo de Implantação de Programas de Educação Ambiental em Empresas: Caso da Bioagri Laboratorios. In: 1o SIMPÓSIO DE PÓS-GRADUAÇÃO EM GEOGRAFIA DO ESTADO DE SÃO PAULO, 2008, Rio Claro. Anais... Rio Claro: UNESP, 2008. Disponível em: http://www. rc.unesp.br/igce/simpgeo/765-781fabio.pdf. Acesso em: 29 de outubro de 2010.

PRESTES, Maria Lucia de Mesquita. A pesquisa e a construção do conhecimento científico: do planejamento aos textos, da escola à academia. $3^{\mathrm{a}}$ ed. São Paulo, Rêspel, 2007.

REIGOTA, Marcos. O que é educação ambiental. São Paulo: Brasiliense, 2009.

SILVA, Ludiana Ribeiro da; COSTA, Josilane Cordeiro; FERREIRA, Rayane Nôleto; ARAÚJO, Mariana Modanês; LIMA, Adda Daniela Figueiredo. Tabuleiro ecológico: educação ambiental através da ludicidade. 2010. Disponível em: http://www2.unucseh. ueg.br/anais/edicao/edicao_vol05_n05/ anais_iniciacaocientifica/geografia/spp_ jic2010_geo_tabuleiro_ecologico_ludiana_josilane_rayane_mariana_adda.pdf. Acesso em: 8 de setembro de 2013.

ZUBEN, F. V. Meio Ambiente, Cidadania e Educação. Departamento de Multimeios. Uni- 